\title{
Lactate detection in the brain of growth-restricted fetuses with magnetic resonance spectroscopy
}

Irene Cetin, MD, PhD; Barbara Barberis, PhD; Valentina Brusati, MD; Erika Brighina, MD; Luca Mandia, MD; Andrea Arighi, MD; Tatjana Radaelli, MD; Pietro Biondetti, MD; Nereo Bresolin, MD; Giorgio Pardi, MD; Mario Rango, MD, PhD

OBJECTIVE: The objective of the study was to determine the feasibility of detecting fetal brain lactate, a marker of fetal metabolic acidemia, using a noninvasive technique, proton magnetic resonance spectroscopy ( ${ }^{1} \mathrm{H}$ MRS), in intrauterine growth-restricted (IUGR) fetuses.

STUDY DESIGN: In vivo human fetal brain lactate detection was determined by ${ }^{1} \mathrm{H}$ MRS in 5 fetuses with IUGR. Oxygenation and acid-base balance data were obtained at birth.

RESULTS: ${ }^{1} \mathrm{H}$ MRS analysis showed the presence of a lactate peak in the brain of the most severely affected IUGR fetus, with abnormal umbil- ical artery Doppler and fetal heart rate tracing. This finding was consistent with the low oxygen content and high lactic acid concentration observed in umbilical blood obtained at delivery.

CONCLUSION: ${ }^{1} \mathrm{H}$ MRS allows the noninvasive detection of cerebral lactate in IUGR fetuses. Lactate detected by ${ }^{1} \mathrm{H}$ MRS may represent a possible marker of in utero cerebral injury or underperfusion.

Key words: brain sparing, fetal brain metabolism, fetal distress, placental insufficiency, pregnancy

Cite this article as: Cetin I, Barberis B, Brusati V, et al. Lactate detection in the brain of growth-restricted fetuses with magnetic resonance spectroscopy. Am J Obstet Gynecol 2011;205:350.e1-7.

M anagement and timing of delivery of intrauterine growth-restricted (IUGR) fetuses remains a central issue for obstetricians, because the risk of perinatal death has to be balanced with the cost of prematurity. ${ }^{1,2}$ Current available surveillance tests seem to have little impact on improving long-term neurodevelopmental outcome. ${ }^{3,4}$ Therefore, new markers of neurological damage should be sought, based on the understanding of the adaptive processes occurring in the human fetal brain during growth restriction.

Proton magnetic resonance spectroscopy $\left({ }^{1} \mathrm{H}\right.$ MRS $)$ is a noninvasive imaging technique that allows obtaining in vivo metabolic information from the brain. ${ }^{5}$ Brain ${ }^{1} \mathrm{H}$ MRS identifies several metabolites of biological importance, including lactate. $^{6}$ It has been demonstrated that elevated levels of lactate detected by ${ }^{1} \mathrm{H}$ MRS in the brain of asphyxiated neonates are predictive of neurodevelopmental delay. ${ }^{7,8}$

Plasma lactic acid concentration is indeed higher in IUGR fetuses with altered umbilical arterial Doppler velocimetry and abnormal fetal heart rate ${ }^{9,10}$; however, litthe is known about intrauterine changes in cerebral metabolism in IUGR fetuses.
From the Magnetic Resonance Spectroscopy Unit (Drs Barberis, Brighina, Arighi, Bresolin, Biondetti, and Rango), the Center for Fetal Research Giorgio Pardi (Drs Cetin, Brusati, Mandia, Radaelli, and Pardi), the Department of Neurological Sciences (Drs Brighina, Arighi, Bresolin, and Rango), the Obstetrics and Gynecology Unit (Drs Radaelli and Pardi), Fondazione IRCCS Ca' Granda-Ospedale Maggiore Policlinico, University of Milan, Milan, Italy and the Obstetrics and Gynecology Unit, Department of Clinical Sciences "L. Sacco" (Drs Cetin and Mandia), University of Milan, Milan, Italy.

Received March 9, 2011; revised April 29, 2011; accepted June 6, 2011.

This study was supported in part by the Italian Ministry of Health Finalized Project OSCAR (2007). Giorgio Pardi, MD died May 1, 2007.

Reprints: Mario Rango, MD, PhD, Department of Neurological Sciences and Magnetic Resonance Spectroscopy Unit, Fondazione IRCCS Ca' Granda-Ospedale Maggiore Policlinico, University of Milan, Milano, Italy. mariocristia@yahoo.it.

0002-9378/\$36.00 • Crown Copyright (C) 2011 Published by Mosby, Inc. All rights reserved. - doi: 10.1016/j.ajog.2011.06.020
In recent years, the fetal brain metabolic profile has been described in utero in uncomplicated pregnancy by ${ }^{1} \mathrm{H}$ MRS during the second and third trimesters. ${ }^{11-14}$ Such studies have failed to detect lactate in the normal fetal brain. However, several authors have recently suggested that the potential evidence of cerebral lactate is an indicator of altered fetal cerebral metabolism in pathological conditions. ${ }^{15-17}$

In this study, we sought to measure fetal cerebral lactate using ${ }^{1} \mathrm{H}$ MRS to evaluate whether it could represent a marker of brain damage in IUGR fetuses.

\section{Materials and Methods}

Patients were enrolled at the Department of Mother Neonate and Child "L. Mangiagalli" of Milano, Italy. Magnetic resonance examinations were performed at the Magnetic Resonance Spectroscopy Unit Fondazione IRCCS Ca' Granda-Ospedale Maggiore Policlinico, University of Milan, Milan, Italy. The study was approved by the Ethical Committee of the Fondazione IRCCS Ca' Granda-Ospedale Maggiore Policlinico, University of Milan, Milan, Italy, and written informed consent was obtained from all patients. 


\section{Study population}

We studied 5 singleton pregnancies complicated by IUGR between 28 and 37 weeks of gestation. Gestational age was calculated from the last menstrual period and confirmed by routine ultrasonography at 11-12 weeks of gestation.

We identified growth-restricted fetuses in utero through repeated longitudinal measurements that demonstrated a reduction in fetal growth velocity and further classified them according to umbilical arterial Doppler velocimetry and fetal heart rate (FHR) tracing. ${ }^{2,10,18}$ Specifically, IUGR was defined by measurements of abdominal circumferences below the 10th percentile of reference values for fetuses of similar ages together with a shift from the growth curve greater than 40 centiles. ${ }^{19}$ As an example, this represents a decrease from the 50th centile (measured at 20 weeks) to below the 10th centile (at the time of IUGR diagnosis). Growth restriction was confirmed at birth, if the neonatal weight was below the 10th percentile according to Italian standards for birth weight and gestational age. ${ }^{20}$ None of the fetuses were affected with abnormal karyotype, genetic syndromes, viral infection, or major malformations.

Antenatal fetal surveillance was conducted by multivessel arterial and venous Doppler velocimetry and FHR evaluation. Doppler waveforms were obtained from uterine arteries, umbilical artery (UA), middle cerebral artery (MCA), and ductus venosus. Uterine arteries Doppler velocimetry was considered altered, if the pulsatility index (PI) was 2 SDs above the mean for gestational age on both sides. UA Doppler waveform was considered abnormal, if the PI was 2 SDs above the mean for gestational age. End-diastolic velocity was classified as either present, absent, or reversed. In the MCA, a PI more than 2 SDs above the mean for gestational age was defined as brain sparing, indicating abnormally reduced impedance to flow in the cerebral circulation. ${ }^{21}$ Ductus venosus velocity during atrial systole was characterized as forward or absent/reversed. ${ }^{21}$

FHR was considered abnormal, if at least 1 of the following patterns was pres- ent: less than 2 accelerations of the heart rate to an amplitude of 10 or more beats per minute lasting 15 seconds or more during a period of at least 30 minutes; variability of 5 or fewer beats per minute during a period of at least 60 minutes; and $U$-shaped (late) decelerations in the heart rate after Braxton Hicks contractions.

IUGR fetuses were classified into 3 groups of increasing clinical severity based on Doppler velocimetry of the umbilical artery and FHR as previously proposed..$^{10}$ Briefly, type 1 IUGR showed both normal PI and FHR; type 2 IUGR had abnormal PI and normal FHR; and type 3 IUGR showed both abnormal parameters.

In the IUGR subjects, the concomitant presence of preeclampsia was defined as the onset of gestational hypertension and proteinuria after 20 weeks of gestation. ${ }^{22}$ Hypertension was defined as 2 or more recordings of a diastolic blood pressure of $90 \mathrm{~mm} \mathrm{Hg}$ or more taken at least 4 hours apart. Proteinuria was considered as the excretion of $300 \mathrm{mg}$ protein or more over a 24 hour period. ${ }^{22}$

Preeclampsia was classified as severe, if 1 or more of the following criteria were present: blood pressure of 160/110 mm $\mathrm{Hg}$ or greater on 2 occasions on bed rest; proteinuria of $5 \mathrm{~g}$ or greater in a 24 hour urine specimen or 3 or greater on 2 random urine samples; oliguria; cerebral or visual disturbances; pulmonary edema or cyanosis; epigastric or right upperquadrant pain; impaired liver function; and thrombocytopenia. ${ }^{23}$

Severe preeclampsia was considered further complicated by HELLP syndrome (hemolysis, elevated liver enzymes, and low platelet count) in the presence of hemolysis (lactate dehydrogenase $>600 \mathrm{U} / \mathrm{L})$, low platelets $(<100,000 / \mu \mathrm{L})$, and elevated liver enzymes (aspartate aminotransferase $>70$ $\mathrm{U} / \mathrm{L})^{24}$

Timing and route of delivery were decided based on maternal and/or fetal parameters, according to our clinical protocol.

Days of hospitalization in the neonatal intensive care unit (NICU) and major neonatal complications were recorded.

\section{MR procedures}

\section{Fetal brain MRI}

All magnetic resonance (MR) examinations were performed on an MR system operating at 1.5 Tesla (Avanto, Siemens, Germany). No fetal sedation was used. Body-phased array coils were used in combination with spinal coils. The standard MR protocol included gradientecho T1-weighted images following the 3 planes of the fetal head and single-shot T2-weighted images (half-Fourier acquisition, single-shot, turbo spin-echo [HASTE] sequence). Three-dimensional T2-weighted images (true fast imaging with steady precession, True-FISP sequence) were also acquired as needed.

\section{Fetal localized brain magnetic resonance spectroscopy (MRS)}

After the standard MRI protocol, to limit the time of the procedure as much as possible, the spectra were acquired with a single volume of interest (VOI) spinecho sequence (PRESS). We located the VOI in the central brain areas (cerebral hemispheres; Figure 1), with the VOI centered on the midline to prevent any possible inclusion of scalp and extracranial tissues. To limit as much as possible any potential contamination from adjacent lipids during the acquisition of brain spectra, we ascertained whether the position of the fetal head was unchanged at the end of the ${ }^{1} \mathrm{H}$ MRS sequence by performing a rapid MRI (localizer) examination ${ }^{12}$ to obtain spectra with a sufficient signal-to-noise ratio (SNR) in the shortest time possible.

Depending on the size of the fetal brain, the volume of the voxel was chosen to be between 10 and $24 \mathrm{cc}$ to acquire MR spectra with sufficient SNR in a reasonable time. Sequences were performed with and without water saturation. The MRS parameters for the water suppressed spectra were as follows: echo time $=135$ milliseconds, repetition time $=4000$ milliseconds, 64 acquisitions. Total acquisition time (imaging and spectroscopy) was limited within 30 minutes in all cases. Data were processed with the use of jMRUI. ${ }^{25}$ The jMRUI is a software package used for the processing of MRS and MRSI data in the time domain (http://www.mrui.uab.es). 
Data processing consisted of zero filling (2048 points), Gaussian filtering (4 $\mathrm{Hz}$ ), Fourier transformation, and zeroorder phase correction. No baseline correction was applied. The presence of the typical lactate signal, visible as an inverted doublet at the echo time used, was searched at $1.33 \mathrm{ppm}$.

Spectra were normalized to the $\mathrm{N}$-acetylaspartate (NAA) peak. NAA is well detected and can be unambiguosly identified by MRS.

\section{Oxygenation and acid-base balance at birth}

Umbilical arterial and venous blood samples were obtained from a clamped segment of the cord immediately after delivery. Blood samples were collected into heparinized syringes and stored on ice until analyses. Fetal hemoglobin concentration $(\mathrm{Hb})$, umbilical arterial and venous oxygen saturation, $\mathrm{pH}, \mathrm{pO} 2, \mathrm{pCO} 2$, and lactate concentration were measured on a GEM Premier 3000 (Instrumentation Laboratory, Lexington, MA). Oxygen content was calculated according to the formula: $\mathrm{O}_{2}$ content (millimoles) $=\mathrm{Hb}$ concentration (grams per liter) $\times \mathrm{O}_{2}$ saturation $\times$ $0.05982 .^{10}$

\section{Statistical analysis}

Data are presented as mean \pm SD. Analyses were performed using SPSS Statistics Desktop (SPSS, Chicago, IL).

\section{Results}

Maternal age ranged between 29 and 35 years (mean, $31.8 \pm 2.3$ years) and maternal body mass index between 18 and $22 \mathrm{~kg} / \mathrm{m}^{2}$ (mean, $20.4 \pm 1.5 \mathrm{~kg} / \mathrm{m}^{2}$ ). Tables 1 and 2 present the characteristics of the IUGR population at the time of MRS study and at the time of delivery, respectively. Gestational age at the time of MRS and at the time of delivery ranged from 28.2 to 37.0 weeks (mean, $32.6 \pm 3.4$ weeks) and from 28.5 to 38.5 weeks (mean, $33.5 \pm 2.5$ weeks), respectively. Time between MRS and delivery was 2-12 days (mean, $5 \pm 4$ days). Femalemale sex ratio was 4:1.

Antenatal Doppler characteristics of each single case are presented in Table 1. Cases 1 and 2 were classified as IUGR type 1 . They presented an abdominal cir-

\section{FIGURE 1 \\ Location of the VOI for MRS}

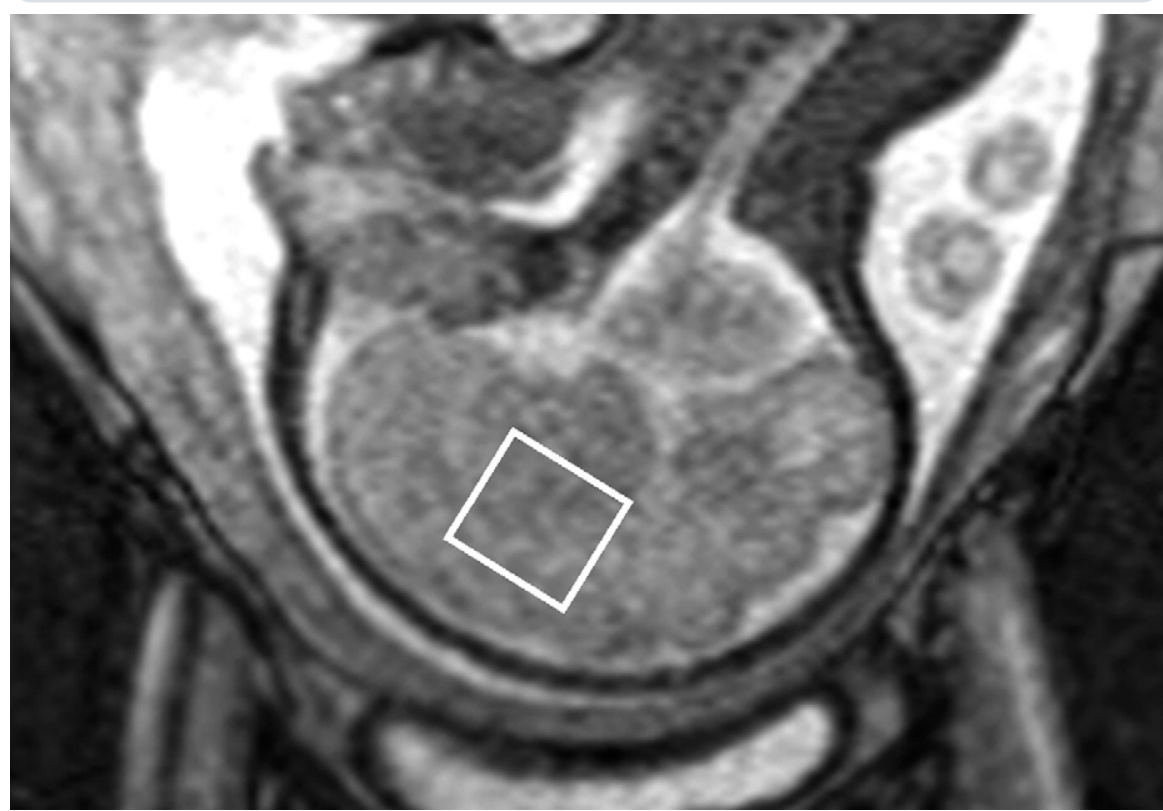

The parasagittal T2-weighted image, case 4, is shown.

MRS, magnetic resonance spectroscopy; VOl, volume of interest.

Cetin. Lactate detection in the human fetal brain. Am J Obstet Gynecol 2011.

cumference between the fifth and 10th percentile of reference values, normal Doppler velocimetry in uterine arteries, umbilical artery, mean cerebral artery and ductus venosus, and normal FHR. Fetus 1 had a single umbilical artery and did not present any major malformations at birth.

In case 2 , the mother was affected by idiopathic thrombocythemia (platelet count approximately $500,000 / \mu \mathrm{L}$ ), which was stable during pregnancy. She developed pregnancy-induced hypertension at 33 weeks of gestational age and was treated with nifedipine $30 \mathrm{mg}$ per os 3 times a day, according to our clinical protocol. At 35 weeks' gestation, she developed mild proteinuria and underwent labour induction at 35.4 weeks' gestation. A dinoprostone vaginal insert was applied and removed 15 hours later because of nonreassuring FHR, and cesarean section was performed.

\section{TABLE 1 \\ Gestational age, antenatal Doppler, and fetal heart rate of IUGR
cases at the time of magnetic resonance spectroscopy}

\begin{tabular}{|c|c|c|c|c|c|c|c|c|}
\hline $\begin{array}{l}\text { IUGR } \\
\text { case no. }\end{array}$ & $\begin{array}{l}\text { GA at } \\
\text { MRS, wks }\end{array}$ & $\begin{array}{l}\text { IUGR } \\
\text { group }\end{array}$ & $\begin{array}{l}\text { Uterine } \\
\text { arteries PI }\end{array}$ & UA & MCA & DV & AF & FHR \\
\hline$\overline{1}$ & 37.0 & 1 & Normal & Normal & Normal & Normal & Normal & $\overline{\text { Reactive }}$ \\
\hline 2 & 35.3 & 1 & Normal & Normal & Normal & Normal & Normal & Reactive \\
\hline 3 & 32.6 & 2 & Altered & AEDF & B.S. & Normal & Oligo & Reactive \\
\hline 4 & 31.3 & 2 & Altered & PEDF & B.S. & Normal & Oligo & Reactive \\
\hline 5 & 28.2 & 3 & Altered & REDF & B.S. & Normal & Oligo & Altered \\
\hline
\end{tabular}

$A E D F$, absent-end diastolic flow; $A F$, amniotic fluid; B.S., brain sparing; $D V$, ductus venosus; FHR, fetal heart rate; $G A$ gestational age; IUGR, intrauterine growth restriction; MCA, middle cerebral artery; MRS, magnetic resonance spectroscopy; oligo, oligohydramnios; PEDF, present-end diastolic flow; PI, pulsatility index; REDF, reverse-end diastolic flow; UA, umbilical artery.

Cetin. Lactate detection in the human fetal brain. Am J Obstet Gynecol 2011 
TABLE 2

Characteristics of the population at delivery

\begin{tabular}{|c|c|c|c|c|c|c|c|}
\hline $\begin{array}{l}\text { IUGR case } \\
\text { no. }\end{array}$ & $\begin{array}{l}\text { GA at delivery, } \\
\text { wks }\end{array}$ & Fetal weight, g & $\begin{array}{l}\text { Placental } \\
\text { weight, } g\end{array}$ & Sex & $\begin{array}{l}\text { Percentile at } \\
\text { birth }\end{array}$ & $\begin{array}{l}\text { Apgar } 1 \\
\text { minute }\end{array}$ & $\begin{array}{l}\text { Apgar } 5 \\
\text { minute }\end{array}$ \\
\hline 1 & 38.5 & 2620 & 280 & $\mathrm{~F}$ & $5-10$ & 9 & 10 \\
\hline $2^{\mathrm{a}}$ & 35.5 & 1910 & 350 & $\mathrm{~F}$ & Less than 5 & 8 & 9 \\
\hline 3 & 33.5 & 1365 & 210 & $\mathrm{~F}$ & Less than 5 & 8 & 9 \\
\hline 4 & 31.5 & 1050 & 265 & $\mathrm{~F}$ & Less than 5 & 8 & 9 \\
\hline 5 & 28.5 & 560 & 100 & M & Less than 5 & 5 & 7 \\
\hline
\end{tabular}

Cases 3 and 4 were classified as IUGR type 2 . They presented a more severe growth restriction than the previous cases (abdominal circumference below the fifth percentile) with oligohydramnios, altered umbilical arterial PI, brain sparing, and normal FHR. Fetus 3 showed mild cerebral ventriculomegaly on ultrasound scan (lateral ventricular size $12 \mathrm{~mm}$ ), which was confirmed by standard MRI. Patient 3 developed preeclampsia at 30 weeks and was treated with nifedipine.

Case 5 was a severe IUGR fetus (IUGR type 3 ) with abdominal circumference below the first percentile, oligohydramnios, and altered umbilical arterial PI and FHR. The mother was affected by severe preeclampsia, had been treated with nifedipine, and developed the HELLP syndrome. Four infants were delivered by cesarean section without labor for fetal indications, and 1 patient underwent cesarean section after labor induction (case 2).

Data at delivery are presented in Table 2. No fetal or neonatal deaths occurred. Ox- ygenation and acid-base balance data at delivery are presented in Table 3 . Case 5, the most severe IUGR fetus (IUGR type 3), presented the lowest oxygen content and the highest lactic acid concentration at birth. Lactic acid concentration was also high at birth in case 4 (IUGR type 2), who was delivered because of altered FHR, and in case 2 (IUGR type 1), a fetus with mild growth restriction who underwent induction of labor, which affected acid-base balance at birth.

Case 1 did not require admission to the NICU. Cases 2 and 3 needed hospitalization in the NICU for 10 and 36 days, respectively, but showed no major neonatal complications. Case 4 experienced respiratory distress syndrome (RDS) and stayed in the NICU 63 days. Case 5 had RDS and underwent 2 episodes of neonatal sepsis. He was discharged from the NICU after 123 days.

\section{MRS studies}

In the cases with less severe IUGR (IUGR types 1 or 2), no lactate peak was detect- able (Table 3). In the most severe case (case 5, IUGR type3), a lactate peak was clearly visible in the spectrum (Table 3 ), as shown in Figure 2.

\section{Comment}

\section{Principal findings}

In this study, we demonstrate a significant lactic acid peak in the brain of a severely growth-restricted fetus. In this patient, MRS was performed at 28 weeks when reverse flow in the umbilical artery was evident and FHR was abnormal. We have previously shown that approximately $80 \%$ of IUGR with these abnormalities are associated with hypoxia and lactacidemia evaluated in utero by fetal blood sampling. ${ }^{10}$

Similarly, our case of severe IUGR showed reduced levels of oxygen content and increased levels of lactic acid in the umbilical artery and vein at the time of delivery (72 hours after MRS) (Table 3 ). Moreover, the finding that lactic acid concentrations were higher in the umbil-

\section{TABLE 3}

Oxygenation, acid-base balance at delivery, and lactate detection by ${ }^{1} \mathrm{H}$ MRS in fetal brain

\begin{tabular}{|c|c|c|c|c|c|c|c|c|}
\hline $\begin{array}{l}\text { IUGR case } \\
\text { no. }\end{array}$ & $\begin{array}{l}\text { IUGR } \\
\text { group }\end{array}$ & UV pH & UA pH & $\begin{array}{l}\text { UV- } \mathrm{O}_{2} \text { cont, } \\
\mathrm{mM}\end{array}$ & $\begin{array}{l}\text { UA- } \mathrm{O}_{2} \text { cont, } \\
\mathrm{mM}\end{array}$ & $\begin{array}{l}\text { UV lac, } \\
\text { mM }\end{array}$ & $\begin{array}{l}\text { UA lac, } \\
\text { mM }\end{array}$ & $\begin{array}{l}\text { Lac peak at } \\
{ }^{1} \mathrm{H} \text { MRS }\end{array}$ \\
\hline 1 & 1 & 7.34 & 7.28 & n.a. & n.a. & 1.1 & 1.3 & - \\
\hline 2 & 1 & 7.33 & 7.27 & 2.3 & 0.7 & 3.4 & 3.6 & - \\
\hline 3 & 2 & 7.33 & 7.25 & 2.8 & 0.3 & 1.5 & 1.8 & - \\
\hline 4 & 2 & 7.36 & 7.28 & 2.5 & 0.8 & 2.8 & 3.2 & - \\
\hline 5 & 3 & 7.31 & 7.28 & 1.2 & 0.4 & 3.1 & 3.6 & + \\
\hline
\end{tabular}

${ }^{1}$ H MRS, proton magnetic resonance spectroscopy; IUGR, intrauterine growth restriction; Lac, lactate; $\mathrm{O}_{2}$ cont, oxygen content; n.a., not available; UA, umbilical artery; UV, umbilical venous; lactate peak absent; + , lactate peak present.

Cetin. Lactate detection in the human fetal brain. Am J Obstet Gynecol 2011. 


\section{FIGURE 2}

Fetal brain lactate detection

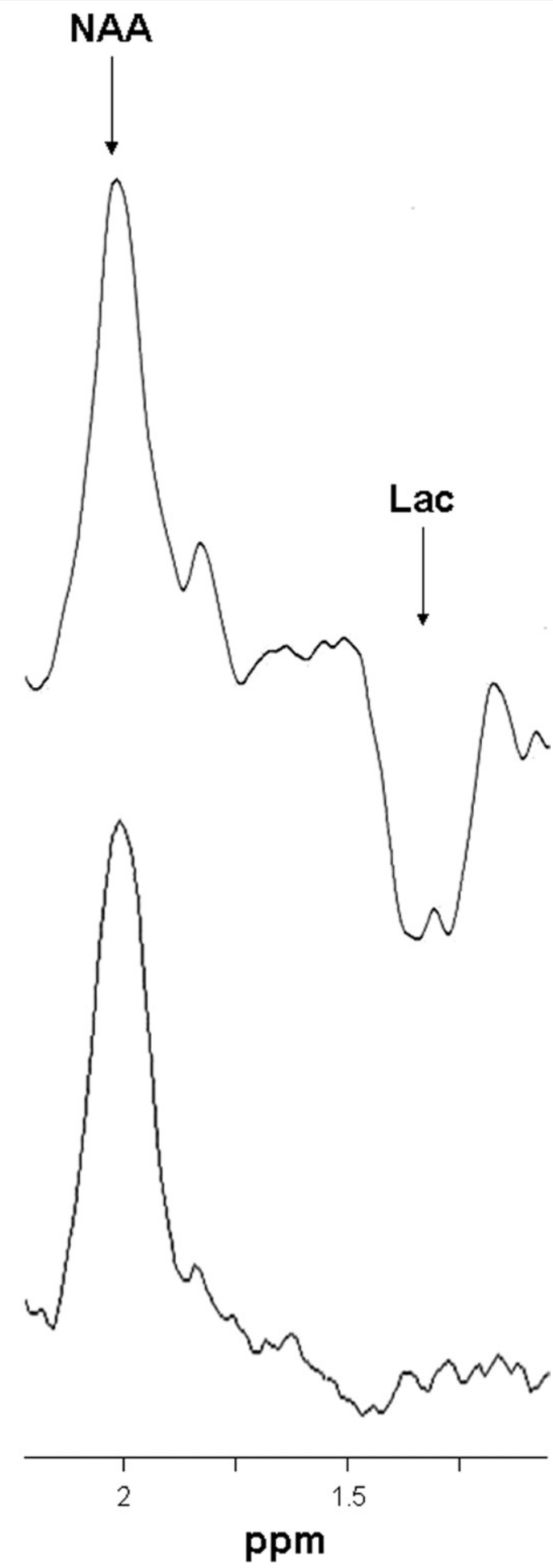

The region of the spectra between 1.00 and $2.25 \mathrm{ppm}$ is represented. $\mathbf{A}$, In the most severe IUGR case (case 5, IUGR type 3), lactate is clearly detectable, because the typical inverted doublet is centered at 1.33 ppm. B, Conversely, no lactate peak is detected in a case of similar gestational age but with a less severe IUGR (case 4, IUGR type 2). Spectra A and B are normalized to the NAA peak.

IUGR, intrauterine growth restriction; $L a c$, lactate; NAA, N-acetylaspartate.

Cetin. Lactate detection in the human fetal brain. Am J Obstet Gynecol 2011. ical artery than in the umbilical vein demonstrates that lactate was produced by the fetus because of anaerobic metabolism, as previously described. ${ }^{9}$

Our finding is in agreement with 2 previous studies that reported the presence of lactate by fetal brain MRS in IUGR fetuses. ${ }^{17,26}$ Both studies, however, lack data about oxygenation and acid-base balance at delivery.

Interestingly, we did not detect any lactic acid peak in the spectra obtained by MRS in the other IUGR fetuses studied, even though we cannot exclude the presence of cerebral lactate in amounts below the minimal level of detection of $0.5-1 \mathrm{mM}$. Although in 2 of these cases umbilical, as well as cerebral, arterial Doppler velocimetry was abnormal and amniotic fluid index was reduced, umbilical oxygen and lactate levels were normal at delivery in 3 of 4 cases in which brain lactate could not be detected by MRS. In only 1 case (case 2), umbilical lactate concentration was high because of the induction of labor, uterine contractions, and consequent fetal distress, as indicated by alterations of FHR before cesarean section was decided. Therefore, hypoxemia at birth in this case was reasonably acute because of the stress of labor.

Caution needs to be applied in making any direct correlation between umbilical lactate concentration measured at birth and brain lactate detected by MRS for several reasons: (1) different intervals of time elapsed between MRS and birth (2-12 days); (2) little knowledge about the mechanisms of lactate transport through the hematoencephalic barrier during intrauterine life ${ }^{27}$; and (3) impossibility of excluding that lactate below the minimal level of detection of $0.5-1 \mathrm{mM}$ is present in the fetal brain. Nevertheless, our results indicate that, in hypoxic IUGR fetuses with increased lactacidemia because of anaerobic metabolism, cerebral lactate is also evident.

Detection of lactate in the fetal brain may indeed represent an indirect sign of energy failure because of reduced adenosine-5' $5^{\prime}$-triphosphate production and mitochondrial function impairment. ${ }^{28}$ In fetal lambs, the degree of cerebral lactate accumulation studied by MRS is as- 
sociated with the severity of hypoxic brain damage. ${ }^{29}$ Newborn piglets with IUGR show increased cerebral lactate during hypoxia, compared with normalweight piglets, and this is inversely associated with the degree of apoptosis, indicating different cerebral metabolism in IUGR brain. ${ }^{30}$

IUGR is a heterogeneous condition, associated with a specific placental phenotype and with different levels of severity. ${ }^{31}$ We have previously shown that a definition of IUGR based on a reduction of growth rate of the abdominal circumference is able to identify fetuses that experience a significant reduction in nutrients delivery and utilization, ${ }^{32,33}$ although not invariably hypoxemic and lactacidemic. ${ }^{10}$ Moreover, whereas redistribution of blood flows with brain sparing occurs, preliminary data now suggest that the fetus adapts to an inadequate environment also with hypometabolism, reducing oxygen consumption on a per-kilogram basis. ${ }^{34,35}$

However, failure of these mechanisms finally occurs and timing of delivery is still the best option to avoid brain damage, although the identification of this time point is still a challenge. Moreover, the ideal marker of brain damage has still to be identified, because neurostructural correlations with observed developmental disabilities have not yet been established. We have recently reported a mild delay in myelination at 40 weeks postconceptional age in IUGR that present brain sparing in utero, with no apparent brain lesions at MRI. ${ }^{36}$

\section{Potential limitations}

A potential limitation of our study is represented by the great variability in gestational age among the IUGR cases. Case 5, the most severe, was also the most premature. However, previous MRS studies have not observed any detectable lactate peak in the brain of normal fetuses at any gestational age in the second half of pregnancy. ${ }^{12}$ Nonetheless, we cannot exlude that lactate is present in the fetal brain at low and nonsignificant levels and may act as a fuel also in normal conditions. ${ }^{37}$

Moreover, the time the MRS and the umbilical blood sampling can represent a potential limitation in making direct correlations between the 2 findings.

\section{Conclusions}

We demonstrated the presence of cerebral lactate detected in vivo in a severe IUGR fetus with hypoxia and lactacidemia at delivery. Lactate detected by MRS may therefore, represent a marker of altered fetal brain metabolism and potential brain damage in IUGR. Further experimental and clinical investigations may help to understand the natural history of IUGR and to evaluate the efficacy of fetal brain MRS in the clinical setting.

\section{ACKNOWLEDGMENT}

This work is dedicated to the memory of Professor G. Pardi who spent much of his time in the design and conduct of this study.

\section{REFERENCES}

1. Fanaroff AA, Stoll BJ, Wright LL, et al. Trends in neonatal morbidity and mortality for very low birthweight infants. Am J Obstet Gynecol 2007;196:147.e1-8.

2. Figueras F, Gardosi J. Intrauterine growth restriction: new concepts in antenatal surveillance, diagnosis, and management. Am J Obstet Gynecol 2011;204:288-300.

3. Walker DM, Marlow N, Upstone L, et al. The Growth Restriction Intervention Trial: long-term outcomes in a randomized trial of timing of delivery in fetal growth restriction. Am J Obstet Gynecol 2011;204:34.e1-9.

4. Baschat AA, Odibo AO. Timing of delivery in fetal growth restriction and childhood development: some uncertainties remain. Am J Obstet Gynecol 2011;204:2-3.

5. Brighina E, Bresolin N, Pardi G, Rango M. Human fetal brain chemistry as detected by proton magnetic resonace spectroscopy. Pediat Neurol 2009;40:327-41.

6. Kreis R, Hofmann L, Kuhlmann B, Boesch C, Bossi E, Hüppi PS. Brain metabolite composition during early human brain development as measured by quantitative in vivo $1 \mathrm{H}$ magnetic resonance spectroscopy. Magn Reson Med 2002;48:949-58.

7. Barkovich AJ, Barnski K, Vigneron D, et al. Proton MR spectroscopy for the evaluation of brain injury in asphyxiated term neonates. AJNR Am J Neuroradiol 1999;20:1399-405.

8. Roelants-van Rijn A, van der Grond J, Stigter R, de Vries LS, Groenendaal F. Cerebral structure and metabolism and long-term outcome in small-for-gestational-age preterm neonates. Pediatr Res 2004;2:285-90.

9. Marconi AM, Cetin I, Ferrazzi E, Ferrari MM, Pardi G, Battaglia FC. Lactate metabolism in normal and growth-retarded human fetuses. Pediatr Res 1990;28:652-6.

10. Pardi G, Cetin I, Marconi AM, et al. Diagnostic value of blood sampling in fetuses with growth retardation. N Engl J Med 1993;328: 692-6.

11. Girard N, Fogliarini C, Viola A, et al. MRS of normal and impaired fetal brain development. Europ J Radiol 2006;57:217-25.

12. Girard N, Gouny SC, Viola A, et al. Assessment of normal fetal brain maturation in utero by proton magnetic resonance spectroscopy. Magn Reson Med 2006;56:768-75.

13. Kok RD, van den Berg PP, van den Bergh AJ, Nijland R, Heerschap A. Maturation of the human fetal brain as observed by $1 \mathrm{H}$ MR spectroscopy. Magn Reson Med 2002;48:611-6.

14. Heerschap A, Kok RD, van den Berg PP. Antenatal MRS spectroscopy of the human brain in vivo. Childs Nerv Syst 2003;19:418-21. 15. Roelants-van Rijn AM, Groenendaal F, Stoutenbeek P, van der Grond J. Lactate in the foetal brain: detection and implications. Acta Paediatr 2004;93:937-40.

16. Wolfberg AJ, Robinson JN, Mulkern R, Rybicki F, Du Plessis. Identification of fetal cerebral lactate using magnetic resonance spectroscopy. Am J Obstet Gynecol 2007;196:e9-11. 17. Azpurua H, Alvarado A, Mayobre F, Salom T, Copel J, Guevara-Zuloaga F. Metabolic assessment of the brain using proton magnetic resonance spectroscopy in a growth-restricted human fetus: case report. Am J Perinatol 2008;25:305-9.

18. Zhang J, Merialdi M, Platt LD, Kramer MS. Defining normal and abnormal fetal growth: promises and challenges. Am J Obstet Gynecol 2010;202:522-8.

19. Todros T, Ferrazzi E, Groli C, et al. Fitting growth curves to head and abdomen measurements of the fetus: a multicentric study. J Clin Ultrasound 1987;15:95-105.

20. Parazzini F, Cortinovis I, Botulus R, Fedele $L$, Decarli A. Weight at birth by gestational age in Italy. Hum Reprod 1995;10:1862-3.

21. Baschat AA, Cosmi E, Bilardo CM, et al. Predictors of neonatal outcome in early-onset placental dysfunction. Obstet Gynecol 2007; 109: 253-61.

22. ACOG practice bulletin. Diagnosis and management of preeclampsia and eclampsia. Obstet Gynecol 2002;99:159-67.

23. Sibai BM. Diagnosis and management of gestational hypertension and preeclampsia. Obstet Gynecol 2003;102:181-92.

24. Sibai BM. Diagnosis, controversies, and management of syndrome of hemolysis, elevated liver enzymes and low platelet count. Obstet Gynecol 2004;103:981-91.

25. Rango M, Cogiamanian F, Marceglia S, et al. Myoinositol content in the human brain is modified by transcranial direct current stimulation in a matter of minutes: a $1 \mathrm{H}-\mathrm{MRS}$ study. Magn Reson Med 2008;60:782-9.

26. Charles-Edwards GD, Jan W, To M, Maxwell D, Keevil SF, Robinson R. Non-invasive detection and quantification of human foetal brain lactate in utero by magnetic resonance spectroscopy. Prenat Diagn 2010;30:260-6.

27. Saunders NR, Hbgood MD, Dziegielwska $\mathrm{KM}$. Barrier mechanism in the brain. II. Imma- 
ture brain. Clin Exp Pharmacol Physiol 1999; 26:85-91.

28. Lane RH, Tsirka AE, Gruetzmacher EM. Uteroplacental insufficiency alters cerebra mitochondrial gene expression and DNA in fetal and juvenile rats. Pediatr Res 2000; 47:792-7.

29. van Cappellen AM, Heerschap A, Nijhuis JG, Oeseburg B, Jongsma HW. Hypoxia, the subsequent systemic metabolic acidosis, and their relationship with cerebral metabolite concentration: an in vivo study in fetal lambs with proton magnetic resonance spectroscopy. Am J Obstet Gynecol 1999;181:1537-45.

30. Moxon-Lester L, Sinclair K, Burke C, Cowin GJ, Rose SE, Colditz P. Increased cerebral lactate during hypoxia may be neuroprotective in newborn piglets with intrauterine growth restriction. Brain Res 2007;1179;79-88.

31. Cetin I, Alvino G. Intrauterine growth restriction:implications for placental metabolism and transport. A review. Placenta 2009;30:S77-82.

32. Cetin I, Ronzoni S, Marconi AM, et al. Maternal concentrations and fetal-maternal concentration differences of plasma amino acids in normal and intrauterine growth retarded (IUGR) pregnancies. Am J Obstet Gynecol 1996;174: 1575-83.

33. Marconi AM, Paolini CL, Stramare L, Cetin I, Fennessey PV, Pardi G. The steady state maternal-fetal leucine enrichments in normal and fetal growth restricted pregnancies. Pediatr Res 1999;46:114-9.
34. Radaelli T, Cetin I, Boito S, et al. Fetal oxygen uptake in normal and IUGR pregnancies. 17th World Congress on Ultrasound in Obstetrics and Gynecology. Ultrasound Obstet Gynecol 2007;30:OC250.

35. Pardi G, Cetin I. Human fetal growth and organ development: 50 years of discoveries. Am J Obstet Gynecol 2006;194:1088-99.

36. Ramenghi LA, Martinelli $A$, De Carli $A$, et al. Cerebral maturation in IUGR and appropriate for gestational age preterm babies. Reprod Sci 2011;18:469-75.

37. Boumezbeur F, Petersen KF, Cline GW, et al. The contribution of blood lactate to brain energy metabolism in humans measured by dynamic $13 \mathrm{C}$ nuclear magnetic resonance spectroscopy. J Neurosci 2010;30:13983-91. 